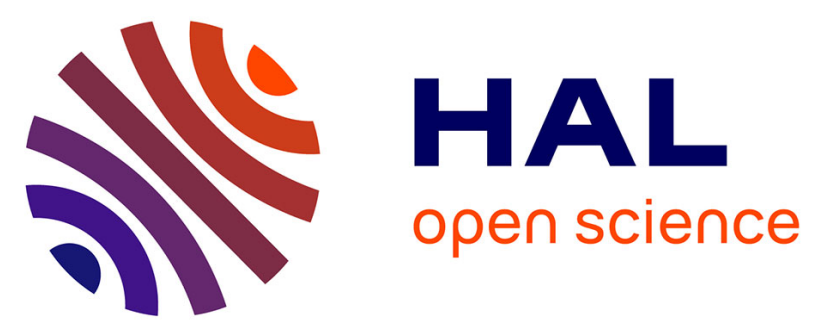

\title{
Influence of the Doping Gas on the Axial Uniformity of the Growth Rate and the Electrical Properties of LPCVD In-Situ Doped Polysilicon Layers
}

\author{
D. Briand, M. Sarret, P. Duverneuil, T. Mohammed-Brahim, K. Kis-Sion
}

\section{- To cite this version:}

D. Briand, M. Sarret, P. Duverneuil, T. Mohammed-Brahim, K. Kis-Sion. Influence of the Doping Gas on the Axial Uniformity of the Growth Rate and the Electrical Properties of LPCVD In-Situ Doped Polysilicon Layers. Journal de Physique IV Proceedings, 1995, 05 (C5), pp.C5-887-C5-893. 10.1051/jphyscol:19955105 . jpa-00253772

\section{HAL Id: jpa-00253772 https://hal.science/jpa-00253772}

Submitted on 1 Jan 1995

HAL is a multi-disciplinary open access archive for the deposit and dissemination of scientific research documents, whether they are published or not. The documents may come from teaching and research institutions in France or abroad, or from public or private research centers.
L'archive ouverte pluridisciplinaire HAL, est destinée au dépôt et à la diffusion de documents scientifiques de niveau recherche, publiés ou non, émanant des établissements d'enseignement et de recherche français ou étrangers, des laboratoires publics ou privés. 


\title{
Influence of the Doping Gas on the Axial Uniformity of the Growth Rate and the Electrical Properties of LPCVD In-Situ Doped Polysilicon Layers
}

\author{
D. Briand, M. Sarret, P. Duverneuil*, T. Mohammed-Brahim and K. Kis-Sion \\ Groupe de Microélectronique et Visualisation, URA 1648 du CNRS, Université de Rennes I, Campus de \\ Beaulieu, Bât. 11B, 35042 Rennes cedex, France \\ * Laboratoire de Génie Chimique, URA 192 du CNRS, ENSIG/INPT, 18 Chemin de la Loge, \\ 31078 Toulouse cedex, France
}

\begin{abstract}
We report in-situ doping of polysilicon grown on glass substrates by a LPCVD process. The growth rate, the resistivity and the dopant concentration of boron in-situ doped polysilicon layers are studied as a function of the deposition pressure and the dopant gas to silane mole ratio. A dependence of the axial uniformity on pressure and $\mathrm{B}_{2} \mathrm{H}_{6} / \mathrm{SiH}_{4}$ mole ratio is put forward, and this effect appears to be very strong especially at high pressure. It is explained by a lowering of the diborane concentration in the gas mixture along the load, because of a different threshold for the thermal decomposition of diborane and silane. It is also put forward that a critical concentration of boron exists above which the growth rate is increasing. Improvements of the horizontal homogeneity are obtained by varying the total gas flow rate.
\end{abstract}

\section{INTRODUCTION}

Polysilicon has found several applications in integrated circuit technology, as gates or emitters in VLSI devices, and it is now used in the fabrication of thin film transistors for active matrix displays [1]. More recently, its interest increased in the studies concerning solar cells because of its potentially better electrical properties than amorphous silicon which is metastable [2,3]. However, having a weaker absorption, it is necessary either to deposit thicker layers of polysilicon, thus to increase the growth rate, or to deposit it on a very large area. Polysilicon grown by the LPCVD method from the decomposition of silane enables us to meet such conditions. Moreover, the in-situ doping, giving an uniform dopant concentration over the whole depth of the layer without a subsequent high-temperature annealing, is suitable for this process, and it is then compatible with the use of low-cost glass substrates. One can then consider the possibility to realize a complete $\mathrm{p}$-i-n structure $i n$-situ. The fabrication of such structures on a large scale requires homogeneous characteristics of the polysilicon on all the substrates, and this condition can be particularly restricted by the used dopant gas.

In the present work, the growth rate, the resistivity and the dopant concentration of boron doped polysilicon layers, as well as their uniformity along the horizontal axis of the reactor, have been investigated. 


\section{EXPERIMENTS}

Polysilicon films were deposited in a 5 inches diameter horizontal hot-wall LPCVD reactor, where the residual pressure is maintained at $3 \times 10^{-5} \mathrm{~Pa}$. A load-lock chamber used to transfer samples enables to keep a permanent clean vacuum in the reactor. A three-zone furnace ensures the regulation of the temperature over a length of $50 \mathrm{~cm}$. The load consisted of two inches glass substrates set at one centimeter intervals and perpendicular to the gas flow in the heated zone. The deposition temperature was fixed at $550{ }^{\circ} \mathrm{C}$. The variable parameters were the total pressure $P$, the gas mole ratio $\Gamma_{0}$ and the total gas flow rate. The range of pressure investigated was from 1 to $90 \mathrm{~Pa}$. Pure silane and phosphine or diborane, both diluted in helium ( $1000 \mathrm{ppm}$ dilution), were injected at the front of the reactor through mass-flow controllers. Unless stated otherwise, the silane flow rate is kept at $50 \mathrm{sccm}$. For each experiment, four samples along the load were investigated in order to examine the axial uniformity. After the growth, samples were annealed in the reactor at $600{ }^{\circ} \mathrm{C}$ for 12 hours. The thickness of the deposited films were measured by a Talystep profilometer and the growth rate was deduced from these values. Resistivity measurements were carried out before and after annealing by a four-point probe with a Keithley 220 current source and a Keithley 617 electrometer. SIMS analysis of the annealed samples gave us the boron concentration.

\section{RESULTS}

\subsection{Boron doping for p-type polysilicon layers}

A complete study of the phosphorus doping of polysilicon under the experimental conditions described above has been carried out and the results are reported elsewhere [4,5]. No significant inhomogeneities are observed. We have studied the boron in-situ doping of polysilicon under the same conditions that in the case of phosphorus doping. The thermal decomposition energy of silane and diborane are respectively 53 $\mathrm{kcal} / \mathrm{mol}$ and $27 \mathrm{kcal} / \mathrm{mol}$ at $550^{\circ} \mathrm{C} \mathrm{[6]}$. It involves necessarily a different behaviour of silane and diborane. One can assume a preferential consumption of diborane, leading to a decrease of the gas mole ratio along the reactor. Then it is not surprising that diborane introduces inhomogeneities when it is used as dopant gas in the LPCVD growth of p-type polysilicon.

The deposition of the films has been carried out at the following total pressures : $1,10,30$ and $90 \mathrm{~Pa}$. The load consists of 24 substrates and we have investigated the substrates set at the position $4,9,14$ and 19 , as indicated on the next graphs.

On the following figures, we represent the variations of the growth rate (Fig. 1.) and of the resistivity (Fig. 2.) along the load for different pressures and for different values of the gas mole ratio $\Gamma_{0}$.

First, it appears that the importance of the inhomogeneities occuring because of the strong consumption of diborane depends on the quantity of diborane injected, but also on the deposition pressure. Indeed, the profiles of both $\mathrm{Vg}$ and $\rho$ differ with these parameters. In the worst case, $\Delta \mathrm{V}_{\mathrm{g}} / \mathrm{V}_{\mathrm{g}}(\mathrm{x})$ is about $10 \%, 30 \%$, $55 \%$ and $16 \%$ for $1,10,30$ and 90 Pa respectively. Concerning the resistivity, $\Delta \rho / \rho(x)$ is $40 \%, 60 \%$, $55 \%$ and $20000 \%$ for the same pressures.

Secondly, as mentionned by several authors who have studied the incorporation of boron in polysilicon with the couple of gas $\left(\mathrm{B}_{2} \mathrm{H}_{6}, \mathrm{SiH}_{4}\right)$, we observe that the growth rate of boron doped films is higher than those of undoped films $[7,8]$. This exaltation effect of diborane seems to be quite dependent on the total pressure since the variation of $\mathrm{V}_{\mathrm{g}}$ with $\Gamma_{0}$ is strongly different in all cases. If we consider the first studied substrate, i.e. at $\mathrm{x}=4 \mathrm{~cm}$, the maximum variation of $\mathrm{Vg}$ are $20 \%, 100 \%, 150 \%$ and $20 \%$ for $1,10,30$ and $90 \mathrm{~Pa}$ respectively. In fact, the dopant element boron is assumed to be the exalting factor of the growth rate [8]. So, it appears that the total pressure plays an important role in the heterogeneous and homogeneous reactions that occur when diborane and silane come in the hot zone, and this leads to a deposition or a "disappearance" of boron. It will be explained later in this paper.

SIMS measurements of boron doped polysilicon layers are reported in table 1 . The boron concentration $\mathrm{C}_{b}$ is given as a function of pressure for different gas mole ratios. SIMS profile shows a constant concentration over the whole depth of the films. The observation of the resistivity profile, which is 
relatively smooth for 1 and $10 \mathrm{~Pa}$ led us to conclude that $\mathrm{C}_{b}$ is constant along the load. However, we performed concentration analysis at $\mathrm{x}=4 \mathrm{~cm}$ and $\mathrm{x}=19 \mathrm{~cm}$ for the films deposited at 30 and $90 \mathrm{~Pa}$ because of the singular profile of the resistivity at these pressures.

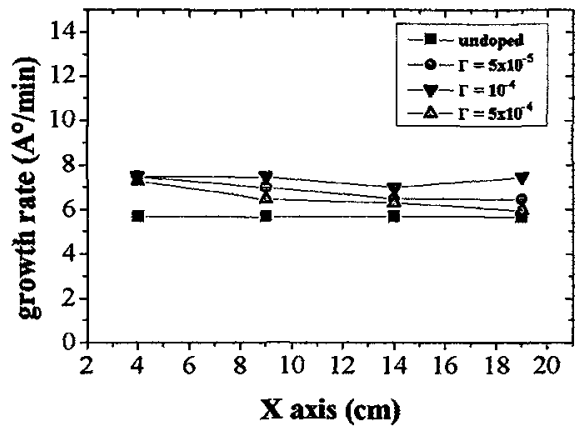

1.a) $\mathbf{P}=1 \mathbf{P a}$

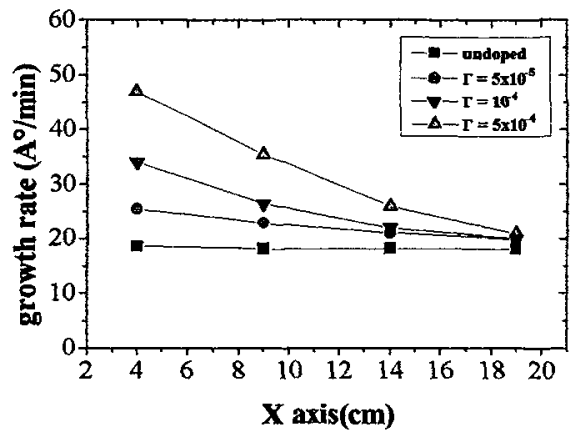

1.c) $\mathrm{P}=30 \mathrm{~Pa}$

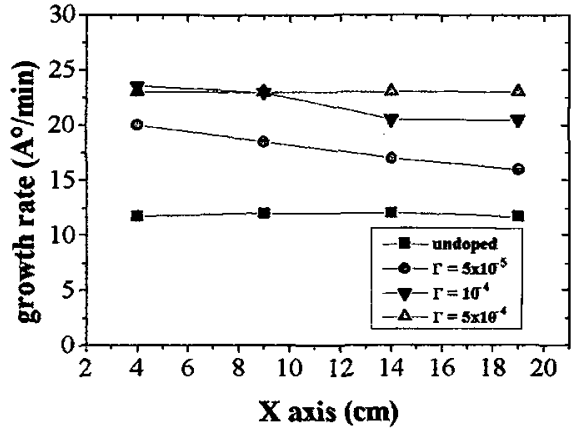

1.b) $P=10 \mathrm{~Pa}$

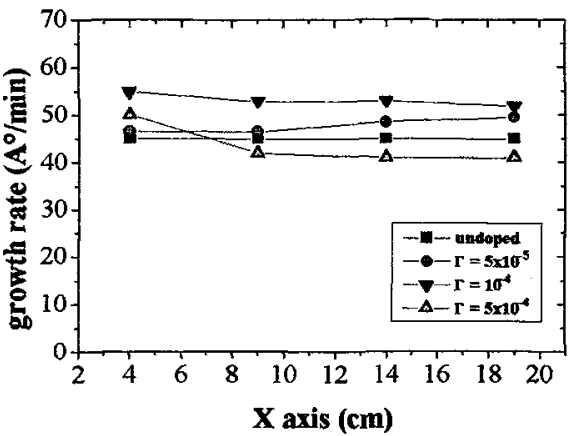

1.d) $\mathrm{P}=90 \mathrm{~Pa}$

Fig. 1. Variation of the growth rate of undoped and doped polysilicon films along the load for several deposition pressures.

\begin{tabular}{|c|c|c|c|c|c|c|}
\hline & $\begin{array}{c}1 \mathrm{~Pa} \\
(\mathrm{x}=\mathbf{4} \mathrm{cm})\end{array}$ & $\begin{array}{c}10 \mathrm{~Pa} \\
(\mathrm{x}=4 \mathrm{~cm})\end{array}$ & $\begin{array}{c}30 \mathrm{~Pa} \\
(\mathrm{x}=4 \mathrm{~cm})\end{array}$ & $\begin{array}{c}30 \mathrm{~Pa} \\
(\mathrm{x}=19 \mathrm{~cm})\end{array}$ & $\begin{array}{c}90 \mathrm{~Pa} \\
(\mathrm{x}=4 \mathrm{~cm})\end{array}$ & $\begin{array}{c}90 \mathrm{~Pa} \\
(\mathrm{x}=19 \mathrm{~cm})\end{array}$ \\
\hline$\Gamma_{\mathbf{0}}=5 \times 10^{-5}$ & $7 \times 10^{19}$ & $10^{20}$ & $7 \times 10^{19}$ & $2 \times 10^{19}$ & $9 \times 10^{18}$ & $4 \times 10^{17}$ \\
\hline$\Gamma_{0}=10^{-4}$ & $1.5 \times 10^{20}$ & $1.5 \times 10^{20}$ & $7 \times 10^{19}$ & $1.5 \times 10^{19}$ & $9 \times 10^{18}$ & $4.5 \times 10^{17}$ \\
\hline$\Gamma_{\mathbf{0}}=5 \times 10^{-4}$ & $6.5 \times 10^{20}$ & $5.5 \times 10^{20}$ & $1.2 \times 10^{20}$ & $5 \times 10^{19}$ & $5 \times 10^{19}$ & $3 \times 10^{18}$ \\
\hline
\end{tabular}

Table 1. Boron concentration in atoms. $\mathrm{cm}^{-3}$ of polysilicon films deposited at different total deposition pressures for three values of the gas mole ratio $\Gamma_{0}=\mathrm{B}_{2} \mathrm{H}_{6} / \mathrm{SiH}_{4}$ ( substrates positions are indicated in parentheses ) 
On one hand, excepted at $1 \mathrm{~Pa}$ where the ratio of $\Gamma_{0}$ is equal to the ratio of $C_{b}$, there is not a sharp correlation between the flow rate of diborane injected and the amount of boron incorporated, and this is true in particular towards high pressures. Moreover, for a similar value of $\Gamma_{0}$, the boron incorporation in the case of low deposition pressures is equal or higher than in the case of high deposition pressures. On the other hand, as expected for $P=30$ and $90 \mathrm{~Pa}, C_{b}$ at $x=4 \mathrm{~cm}$ is higher than $C_{b}$ at $x=19 \mathrm{~cm}$. This suggests that the relative concentrations of the different species in the gaseous medium probably change along the hot zone of the reactor, and it confirms the influence of the deposition pressure on the mechanisms that rule boron incorporation.

The resistivity of the boron doped layers is reported on figure 2 . In order to compare the values of the resistivity of the different samples, it is necessary to take into account the crystalline structure of the silicon deposited. Indeed, previous works have shown that silicon deposited amorphous and then annealed have better electrical properties than silicon deposited polycrystalline [9]. Moreover, the structural state of silicon after deposition depends on the pressure [10] and it is known that boron promotes the crystallization of silicon [11]. Comparison of the resistivity before and after annealing led us to conclude that :

- at a deposition pressure of 1 and $10 \mathrm{~Pa}$, layers are deposited polycrystalline whatever $\Gamma_{0}$.

- at $\mathbf{P}=90 \mathrm{~Pa}$, layers are deposited amorphous whatever $\Gamma_{0}$.

- at $\mathbf{P}=30 \mathrm{~Pa}$, samples set in the front part of the load are deposited polycrystalline and those set in the rear part are amorphous deposited. The number of substrates deposited polycrystalline varies with $\Gamma_{0}$.

In first approximation, resistivities are constant along the $\mathrm{x}$ axis and are well correlated with the SIMS results for $P=1$ and $10 \mathrm{~Pa}$. For $\mathrm{P}=90 \mathrm{~Pa}$, the resistivity increases along the load and the lower $\Gamma_{0}$ is, the stronger this effect. The value of resistivities is also correlated with the boron concentration.

The incurved shape of figure 2.c), i.e. when $P=30 \mathrm{~Pa}$ is explained by the different crystalline state of the films deposited. Although the sample 4 presents a higher boron concentration than the sample 19 , they have nearly the same resistivity since the sample 4 has been deposited crystalline while the sample 19 has been deposited amorphous. In this case, the better crystalline structure balances the lack of boron atoms.

Concerning the radial uniformity, the relative variations of $V_{g}$ and $\rho$ do not exceed $10 \%$, except for $\mathbf{P}=90 \mathrm{~Pa}$, where $\Delta \rho / \rho(y, z)$ can be $30 \%$.

\subsection{Effect of the total gas flow rate}

Experiments have been carried out by varying the total gas flow rate. The experimental parameters were $P=90 \mathrm{~Pa}$ and $\Gamma_{0}=5 \times 10^{-5}$. Figure 3 shows the results for three values of the total gas flow : 50, 100 and $150 \mathrm{sccm}$. The growth rate of polysilicon is not very affected. However, the profile of the resistivity is significantly improved, and its level is decreased. For $\Gamma_{0}=150 \mathrm{sccm}$, boron concentrations are $4 \times 10^{19}$ and $4 \times 10^{18}$ atoms. $\mathrm{cm}^{-3}$ for the samples 4 and 19 respectively. Thus, an increase of the total gas flow rate leads to an increase of the incorporation rate and reduces the variation of $\mathrm{C}_{b}$ along the load.

\section{DISCUSSION}

We have calculated the relative consumption of silane due to a deposition on all the surfaces in the hot zone, i.e. on the quartz tube and on the substrates. For a flow rate of $50 \mathrm{sccm}$, and when the growth rate is maximum, only $5 \%$ of the silane injected in the reactor contribute to the growth of silicon. The flat profile of the growth rates of undoped silicon for all the pressures, reported on figure 1, confirms that the quantity of silane injected is quite enough to feed all the surfaces and thus, the variations of $\mathrm{Vg}$ for doped films is not a consequence of a lowering of silane concentration along the axis.

We have plotted on figure 4 the growth rate as a function of the boron concentration for $\mathrm{P}=30 \mathrm{~Pa}$. It appears clearly that there is a critical concentration, about $7 \times 10^{19}$ atoms. $\mathrm{cm}^{-3}$, above which the growth rate 


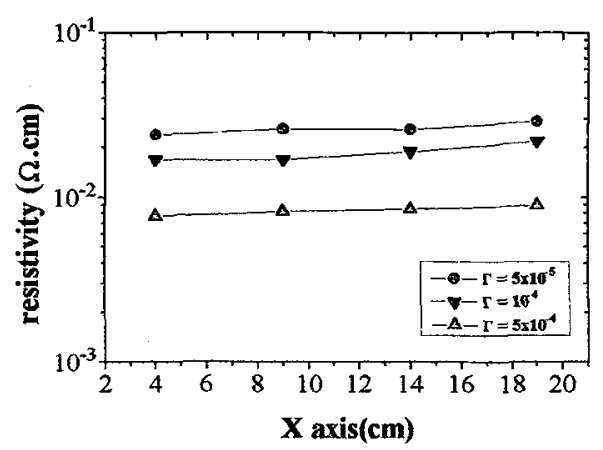

2.a) $\mathrm{P}=1 \mathrm{~Pa}$

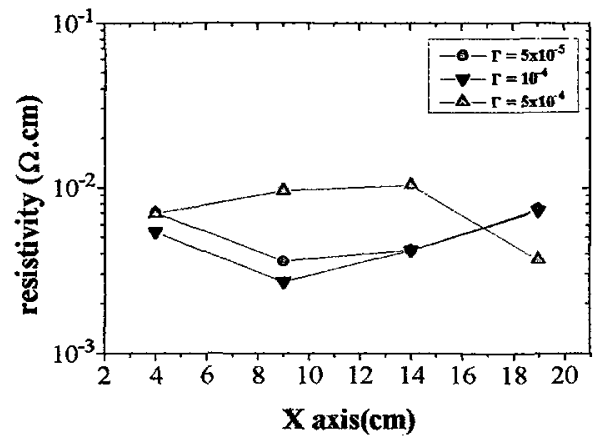

2.c) $\mathrm{P}=30 \mathrm{~Pa}$

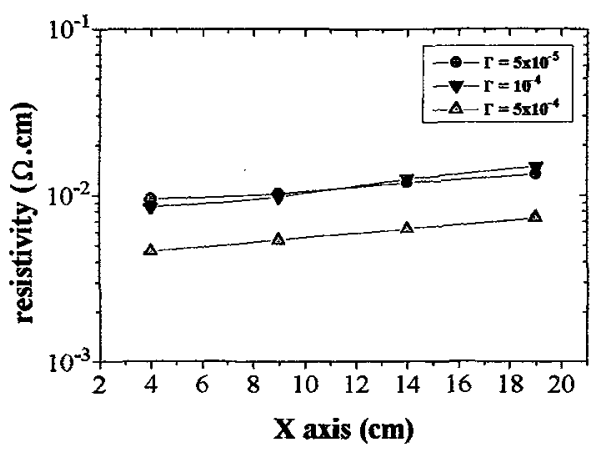

2.b) $P=10 P a$

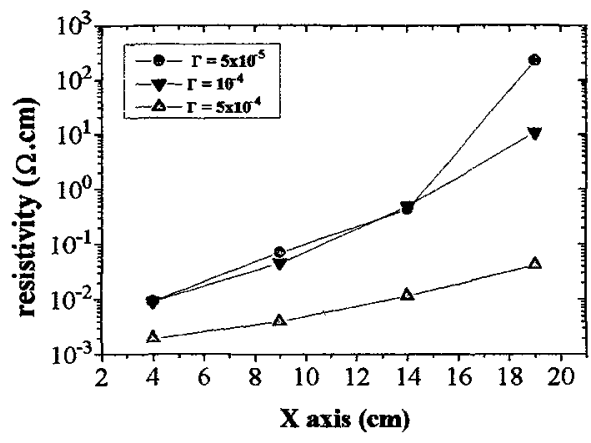

2.d) $P=90 P a$

Fig. 2. Variation of the resistivity of doped polysilicon films along the load for several deposition pressures.
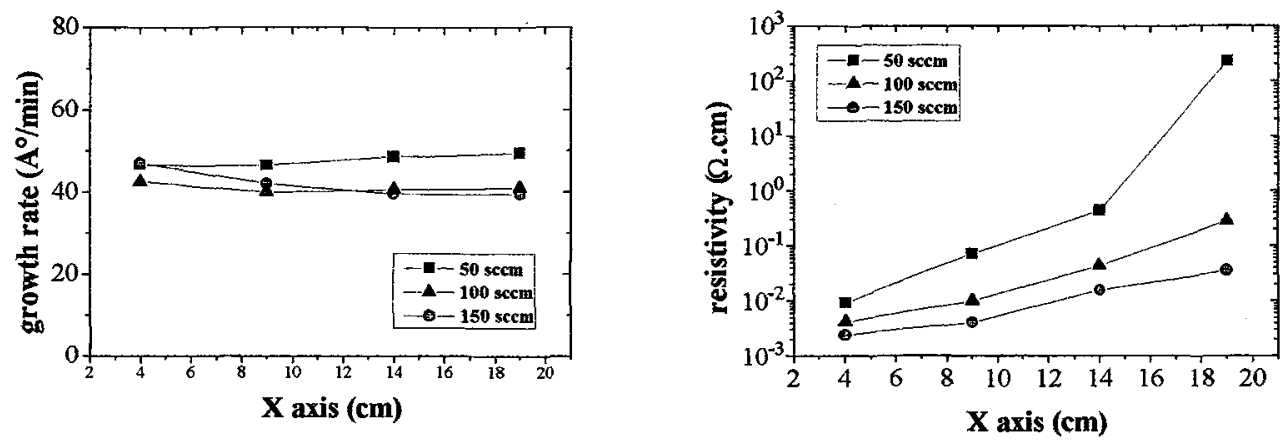

Fig. 3. Effect of the gas flow rate on the growth rate and on the resistivity for $\mathrm{P}=90 \mathrm{~Pa}$ and $\Gamma_{0}=5 \times 10^{-5}$. 
is sharply exalted. Below this concentration, the growth rate is almost constant. For 1 and $10 \mathrm{~Pa}$, this effect is more difficult to put forward. We suggest that the intensity of this increase is a growing function of the pressure. However, at $\mathbf{P}=90 \mathrm{~Pa}$, no significant exaltation is observed. This can be easily explained since the maximum value of $C_{b}$ measured is $5 \times 10^{19}$ atoms.cm ${ }^{-3}$, less than the threshold of concentration. One aspect that we did not investigate until now is the flow velocity of gas $V_{d}$ in the reactor. It is a function of the pressure $P$ and the total flow rate $\Phi$ as :

$$
V d(m / s)=0.508 \frac{\Phi(s c c m)}{P(P a)}
$$

When $\Phi$ is fixed at $50 \mathrm{sccm}$ and $P$ varies from 1 to $90 \mathrm{~Pa}, V_{d}$ varies from 25.4 to $0.28 \mathrm{~m} / \mathrm{s}$. Then, the residence time of the gas in the hot zone before the load is very different, so this zone, which has a length of $10 \mathrm{~cm}$, might have a large importance. We can assume that diborane is adsorbed without decomposition. One can also consider that homogeneous reactions occur, giving either species that will contribute to the deposition or other species that will trap boron. These different mechanisms determine the flow ratio along the axis, that is the relative consumption of diborane and silane. Let us calculate a flow ratio $\Gamma(x)$ by considering that each molecule of diborane injected gives two atoms of boron in the layer. $\Gamma(\mathrm{x})$ is given by the following expression :

$$
\Gamma(x)=\Gamma 0-\frac{1}{2} \cdot \frac{A(x)(m o l / s)}{\Phi_{\text {SiH }}(\mathrm{mol} / \mathrm{s})}
$$

where $A(x)$ is the amount of diborane consumed before the substrate $x$. Figure 5 shows the relation between $\Gamma(x)$ and $C_{b}$. No variation of $\Gamma(x)$ is established. This result is inconsistent with the previous hypothesis since we should have observed a strong dependence of $\Gamma(x)$ with $C_{b}$. It is likely that homogeneous reactions induce a trapping of boron by forming molecules like silylboranes $[12,13]$. These reactions are more efficient at high pressure since molecular mean free-path is low. As the residence time is higher at $90 \mathrm{~Pa}$ than at $1 \mathrm{~Pa}$, consumption of diborane might be stronger in the hot zone before the load

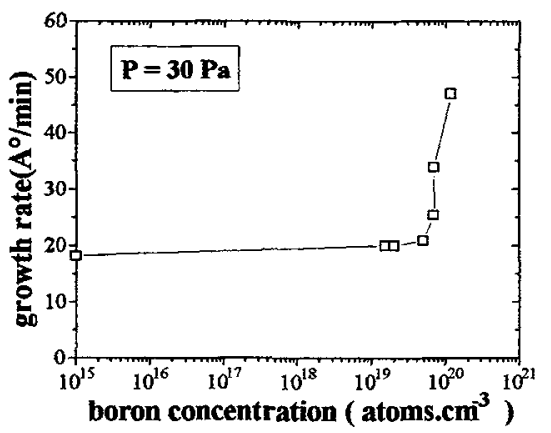

Fig. 4. Variation of the growth rate with the boron incorporation rate at $\mathbf{P}=30 \mathrm{~Pa}$.

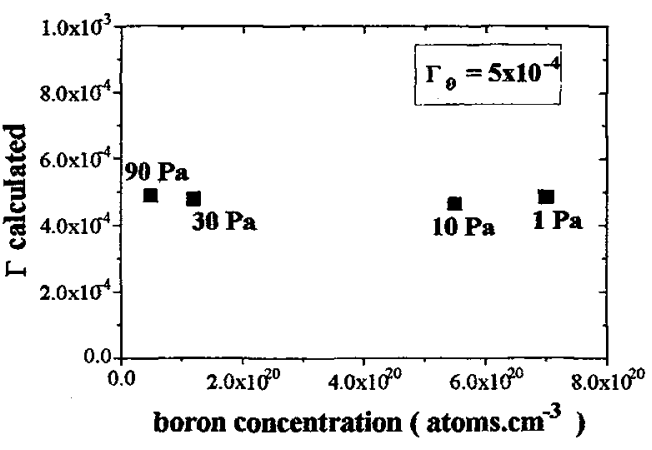

Fig. 5. Variation of the $\Gamma(x)$ calculated for the different pressures at $x=4 \mathrm{~cm}$.

when the deposition is achieved at a high pressure. Thus, it is normal to find a weaker boron concentration at $90 \mathrm{~Pa}$ than at $1 \mathrm{~Pa}$. Rising the total flow rate could contribute to restore the flow ratio.

However, hypothesis on the growth rate and the boron concentration in the front part of the reactor have been made. It will be necessary to plan further experiments to determine the true values of $V_{g}$ and $C_{b}$ at the beginning of the heated zone. 


\section{CONCLUSION}

We have studied in situ boron doping of LPCVD polysilicon using the $\mathrm{SiH}_{4}+\mathrm{B}_{2} \mathrm{H}_{6}$ chemistry. The doped layers are assigned to the fabrication of $\mathrm{p}-\mathrm{i}-\mathrm{n}$ diodes used in solar conversion. We showed that the exaltation of the growth rate with boron occur above a threshold concentration. The incorporation rate depends on the deposition pressure which rules the homogeneous reactions. At low pressures, no major problem is observed. However, it is more advisable to grow silicon at high pressures since its electrical properties are better and the growth rate higher. The problems of axial homogeneity met in this range of pressure have led us to enter upon a study with injection set-up. It is currently in progress and will be presented in a future publication.

\section{References}

[1] Yamauchi N. and Reif R., J Appl Phys, 75 (1994) 3235-3257.

[2] Matsuyama T., Wakissada K., Kaneda M., Tanaka M., Matsuoka T., Tsuda S., Nakano S., Kishi Y.and Kuwano Y., Jpn. J. Appl. Phys. 29 (1990) 2327.

[3] Morikawa H., Itagaki T., Kawabata K., Ishihara T., Sato K. and Namizaki H., Solor Energy Materials 23 (1991) 199-205.

[4] Sarret M., Liba A., Le Bihan F., Joubert P. and Fortin B., Journal of Applied Physics 76.(1994) $5492-5497$

[5] Briand D., Sarret M. Le Bihan F., Bonnaud O. Pichon L., to be published in Mat. Scienc. Tech.

[6] Branz H.M., Flint J.H., Harris C.J., Haggerty J.S. and Adler D., Appl. Phys. Lett. 51 (1987) 922-924

[7] Hall L.H. and Koliwad K.M., J Electrochem. Soc. 120 (1973) 1438-1440.

[8] Eversteyn F.C. and Put B.H., J. Electochem. Soc. 120 (1973) 106-110.

[9] Sarret M., Liba A., Bonnaud O,, Le Bihan F.and Fortin B., "Comparison of physical and electrical properties of ULPCVD and VLPCVD in-situ phosphorus doped polysilicon or undoped polysilicon" EUROCVD NINE, Tampere, Finland, 22-27 August 1993, T. Mäntylä Eds. (Les Editions de Physique, Les Ulis, 1993) pp 411-417.

[10] Joubert P., Loisel B., Chouan Y. and Haji L., J Electrochem. Soc. 134 (1987) 2541-2544.

[11] Bisaro R., Magariño J., Zellama K., Squelard S., Germain P. and Mohrange J.F., Phys. Rev. B 31 (1985) 3568 .

[12] Bock C.W., Trachtman M. and Mains G.J., J. Phys. Chem. 89 (1985) 2283.

[13] Bock C.W., Trachtman M., Maker P.D., Niki H. and Mains G.J., J. Phys. Chem. 90 (1986) 5669. 